\title{
Ecological Populations of Bacteria Act as Socially Cohesive Units of Antibiotic Production and Resistance
}

Cordero Otto X. ${ }^{1}$, Wildschutte Hans ${ }^{1}$, Kirkup Benjamin ${ }^{1}$, Proehl Sarah ${ }^{1}$, Ngo Lynn ${ }^{1}$, Hussain Fatima ${ }^{1}$, Le Roux Frederique ${ }^{2}$, Mincer Tracy ${ }^{3}$, Polz Martin F. 1, *

${ }^{1}$ MIT, Dept Civil \& Environm Engn, Cambridge, MA 02139 USA.

2 Inst Francais Rech Exploitat Mer, Lab Genet \& Pathol BP 133, F-17390 La Tremblade, France.

${ }^{3}$ Woods Hole Oceanog Inst, Dept Marine Chem \& Geochem, Woods Hole, MA 02543 USA.

* Corresponding author : Martin F. Polz, email address : mpolz@mit.edu

\begin{abstract}
:
In animals and plants, social structure can reduce conflict within populations and bias aggression toward competing populations; however, for bacteria in the wild it remains unknown whether such populationlevel organization exists. Here, we show that environmental bacteria are organized into socially cohesive units in which antagonism occurs between rather than within ecologically defined populations. By screening approximately 35,000 possible mutual interactions among Vibrionaceae isolates from the ocean, we show that genotypic clusters known to have cohesive habitat association also act as units in terms of antibiotic production and resistance. Genetic analyses show that within populations, broad-range antibiotics are produced by few genotypes, whereas all others are resistant, suggesting cooperation between conspecifics. Natural antibiotics may thus mediate competition between populations rather than solely increase the success of individuals.
\end{abstract}




\section{Main Text:}

The ratio of intra- versus interspecific competition is a key element regulating populations and determining their success within diverse communities. It is especially important in structured animal and plant populations, where closely related individuals live in patches and encounter each other often (1). In these cases, modulation of intra-specific antagonism or cooperation can mitigate the detrimental effects of niche overlap. However, for bacteria in the wild, it has been postulated that populations merely represent loose assemblages of individuals driven by ecological opportunity $(2,3)$. The reasons given include high dispersal rates and rapid horizontal gene transfer (HGT), which both can rapidly erode population structure by mixing unrelated individuals and introducing novel, potentially advantageous genes to their genomes. This may initiate a dynamic process of rapid, but locally and/or temporarily limited expansion of 
individuals (clones). A classical example of such interactions is interference competition via colicin-type bacteriocins $(4,5)$, which are almost always encoded by plasmids and are able to kill closely-related competitors in a highly specific manner. In these cases, population dynamics are primarily driven by the cyclic invasion of antibiotic production and resistance genes. Similarly, a recent high-throughput screen of mutual interactions among soil isolates indicated changing types of interactions occur over relatively short evolutionary distances. This was interpreted as short-lived dynamics of gene gain and loss, where antibiotic-production selects resistance, which subsequently promotes loss of production and reversion to sensitivity (6). In contrast to this gene-centric view of bacterial population dynamics, recent fine-scale environmental mapping of bacterial diversity has suggested that population structure may exist beyond individual clones. Such ecologically defined populations consist of phylogenetic clusters of closely related but nonclonal individuals, which share common ecological associations $(7,8)$. However, it remains unknown whether individuals within such populations interact sufficiently strongly to allow for the development of cohesive population-level social organization akin to structured animal and plant populations.

Here, we asked whether ecologically defined populations show social cohesion beyond association with similar sets of resources. We reasoned that an obvious and important test case would be interference competition mediated by antibiotic production. This required mapping the network of potential antagonistic interactions between bacteria onto their fine-scale genotypic structure in the environment. Thus far, such an exercise has been impeded by the lack of data on genotypically and ecologically delineated natural microbial populations. In recent years, however, we have taken bacteria of the family Vibrionaceae as a model for the ecology and 
evolution of bacterial populations (8-10). These populations were originally identified using an unsupervised machine learning approach that combines genetic similarity and micro-habitat specialization to cluster clades with cohesive ecology (8) in a way that is agnostic to any preconceived notion of species. The populations thus identified consist of groups of individuals coexisting in micro-habitats and closely related in protein housekeeping gene sequences (genotypic clusters). Many of these clusters cannot be differentiated by the most commonly used marker for phylogenetic classification of microbes, the rRNA gene, suggesting recent evolutionary age (8). Importantly, although these genotypic clusters are distinguished by their propensity to occur as free-living or associated with different types of suspended organic particles and zooplankton $(8,11)$, they co-occur in the guts and on the surfaces of larger marine animals (11). Because of their genotypic cohesion and differential environmental distributions, these clusters are hypothesized to represent natural populations and provide a platform to inquire whether factors beyond similarity in environmental association enforce population structure.

We first determined the potential for interference competition among individuals from different populations by measuring antagonistic interactions in an all-against-all framework using 185 Vibrio isolates that have been characterized to high genetic resolution by sequencing of several protein-coding, housekeeping genes (table S2). We used the classic Burkholder plate assay (12, 13), which allows testing for local growth inhibition between bacteria co-plated on nutrient agar (14). Testing inhibition in this way provides somewhat realistic conditions for ocean bacteria, since interference competition is most likely to occur among individuals co-existing on particle surfaces or in the guts of animals, where local population density can be high (13). After screening $\sim 35,000$ possible interaction pairs, we obtained a large network containing 830 
antagonistic interactions between naturally co-occurring Vibrio strains (individual genotypes). Replication of the antagonism assay for a selected number of strains showed this data to be very robust, with more than $97 \%$ replicability of interactions (14). The data show that nearly half (44\%) of the strains were able to inhibit at least one other strain, while $86 \%$ were inhibited by at least one strain. A few $(<5 \%)$ 'super-killer' strains were able to inhibit more than $25 \%$ of all other strains in the collection (Fig. 1A). Using a membrane diffusion method (14), we estimate that $96 \%$ of the antagonistic interactions are mediated by small molecules and not by proteins such as bacteriocins.

Mapping the network of antagonistic interactions onto the fine scale genotypic structure of the tested strains shows that the potential for interference competition is much lower within natural populations than between them. This is expressed by the conditional probability of observing an antagonistic interaction as a function of genetic distance, $\mathrm{P}(\mathrm{A} \mid d)$ (Fig. 1b), where distances were computed based on a concatenated alignment of six housekeeping genes. $\mathrm{P}(\mathrm{A} \mid d)$ has a sigmoidal shape, with a 4-5 fold reduction in the probability of observing antagonism over relatively short genetic distances. Despite the strong influence that super-killer strains have on these data, this trend holds when considering only narrow range antagonists with $\leq 5$ inhibited strains (Figure $\mathrm{S} 1)$, and the bias to long-distance killing is statistically significant $(\mathrm{p}=0.001)$ even when controlling for phylogenetic structure and killing activity per strain (14). The sharp increase in P $(\mathrm{A} \mid d)$ at a threshold distance indicates that a natural genetic boundary exists for interference competition. Remarkably, this boundary coincides almost exactly with the average value of $d$ between strains in different populations, $\boldsymbol{d}_{p o p}$, that is, the average genetic boundary between 
ecologically cohesive genotypic clusters determined in previous studies $(8,10)$ (Fig 1C). This means that antagonism occurs mostly between rather than within natural Vibrio populations.

The observed low antagonism within populations is not a result of resistance between near-clonal strains as would be expected from dynamics of clonal expansion followed by gradual gene loss (6). Although the Vibrio populations consist of isolates with high sequence similarity in the set of shared genes, there is significant gene content diversity between strains. In 41 sequenced genomes representing 10 Vibrio populations (table S4), we find that although populations are clustered by gene content, the average percentage of shared genes between genomes at distances $<\boldsymbol{d}_{p o p}$ is only $72 \%$ (Figure S2). Moreover, these genomes are highly recombinogenic and show no evidence of a clonal origin (15). This implies that the pattern of low intra-population antagonism is not likely to be explained by simple vertical inheritance and gene loss; rather, this pattern is generated and maintained in a regime of fast allelic turnover and potential for losing and acquiring new genes.

To further explore whether antibiotic production might have co-evolved with populations or was horizontally acquired, we increased the isolate sampling around the most prolific super-killer in our collection, strain 12B09, belonging to a population of $V$. ordalii. We added a tight cluster of 29 highly related co-isolates $(d<0.01)$, which we used to study the population genomics of the super-killer phenotype. Using random transposon mutagenesis, we identified the genetic basis of antibiosis in 12B09 and studied its evolution using whole genome sequences of both producers and non-producers. This genomic approach was complemented with chemical screening and identification of active compounds. 
By screening a library of 20,000 12B09 transposon mutants against a sensitive indicator strain, we identified 10 mutants with no antagonistic activity, which all had transposon insertions within a hybrid polyketide synthase (PKS) / non-ribosomal peptide (NRP) gene cluster (Figure 2A). A genetic knock-out of the central NRP biosynthesis gene shows complete loss of activity, demonstrating a single specific antibiotic biosynthesis cluster is responsible for the antagonistic activity. This is consistent with results obtained from screening a chemical extract from cell-free 12B09 supernatant separated by high performance liquid chromatography, showing that $100 \%$ of the activity could be accounted for by a single peak. Accordingly, this peak was absent from the knockout mutant 12B09-HW44, which had no antibiotic activity (Figures S4-5). Genes in the PKS-NRP cluster possess sequence similarity to cyclic lipopeptide antibiotic synthases, which typically cause membrane depolarization or pore formation, triggering cell lysis (16).

Using the cluster of 29 highly related strains from the expanded $V$. ordalii population, we obtained a high-resolution all-against-all antagonism network comprising 91 strains subdivided roughly equally across three populations of $V$. ordalii, $V$. crassostreae and $V$. tasmaniensis (table S3). This network revealed that the super-killer phenotype is present in a small fraction (5 out of 29 ) of the highly related strains within $V$. ordalii (Figure 2B), and was absent in any of the other populations. Moreover, all $V$. ordalii strains were resistant, confirming our previous result at a much higher genetic resolution level. A PCR screen with multiple specific primers diagnostic for the PKS-NRP biosynthetic cluster confirmed that this specific pathway is found in all of the five super-killers identified in the plate assays, and not in any of the other V. ordalii strains (14). This was consistent with data from the 185 strain network (Fig. 1A) showing that individuals resistant to each other did not antagonize the same set of strains (Pearson's $\varphi=0.04$ ). Overall, this result 
shows that the super-killer phenotype in the population is caused by differential presence/ absence of genes, not by transcriptional regulation or silencing mutations.

The study of sequenced genomes from two super-killers and three resistant conspecifics confirmed our prediction that recent horizontal gene transfer mediated the acquisition of production and resistance genes in $V$. ordalii. Different lines of evidence supported this. First, a whole genome phylogeny of the sequenced strains (Figure S3) showed that super-killers share a recent common ancestor, suggesting that the gene cluster is not ancestral to the population but that it was acquired in a single recent event. Second, BLAST (17) searches against public databases of fully sequenced genomes identified the antibiotic cluster only in two previously sequenced Vibrio isolates from the Pacific Ocean with very low genomic similarity to $V$. ordalii: the shellfish pathogen $V$. tubiashii, and the particle attached SWAT-3 $(14,18)$. Third, a whole genome alignment of 12B09 and SWAT-3 revealed a collinear and conserved fragment of $16.3 \mathrm{~Kb}$ containing only the antimicrobial cluster, which indicated recent acquisition. Moreover, in SWAT-3 the antimicrobial peptide cluster is flanked by a large arrangement of transposases and integrases (Fig 1B), suggesting that the cluster comprises a mobile element, which was recently acquired in different Vibrio populations across distant regions of the ocean. Importantly, the resistance factors did not appear to be coded within the same mobile cluster, since none of the genes in the cluster were present in the resistant but non-producing $V$. ordalii strains. This suggested that these genes for antimicrobial production are unlinked from their resistance factors and can only invade in populations where some individuals carry pre-adaptations that enable them to survive the acquisition of antimicrobial production genes. 
Contrary to the widespread idea that bacterial populations are driven by gene centric and selfish dynamics, we have shown that ecological populations defined by common microhabitat association also represent socially interacting units. Although it remains unknown how widespread the observed phenomenon is, low frequency of antagonism within short genetic distances has also recently been observed among Streptomyces isolates (6). Our results indicate that, similar to the case of marine vibrios, this pattern could reflect the ecological and genetic boundaries of structured populations and not a transient gene-centric dynamic (6). The fact that each antibiotic is produced by only a small fraction of the population while the rest is resistant supports the hypothesis that antibiotics can constitute public goods within populations, benefiting non-producing but resistant conspecifics. Importantly, such social structure mediates competition between ecological populations rather than benefiting only the carrier of the antibiotic production

gene. Finally these result suggests that the ecological population structure of bacteria in the wild is much stronger than previously assumed.

\section{References and Notes}

1. C. E. Tarnita, T. Antal, H. Ohtsuki, M. A. Nowak, Evolutionary dynamics in set structured populations. Proceedings of the National Academy of Sciences of the United States of America 106, 8601 (May 26, 2009).

2. W. F. Doolittle, Eradicating typological thinking in prokaryotic systematics and evolution. Cold Spring Harbor symposia on quantitative biology 74, 197 (2009).

3. W. F. Doolittle, O. Zhaxybayeva, Metagenomics and the units of biological organization. BioScience 60, (2010). 
4. E. Cascales et al., Colicin biology. Microbiology and molecular biology reviews : MMBR 71, 158 (Mar, 2007).

5. B. Kerr, M. A. Riley, M. W. Feldman, B. J. Bohannan, Local dispersal promotes biodiversity in a real-life game of rock-paper-scissors. Nature 418, 171 (Jul 11, 2002).

6. K. Vetsigian, R. Jajoo, R. Kishony, Structure and evolution of streptomyces interaction networks in soil and in silico. PLoS biology 9, e1001184 (Oct, 2011).

7. A. Koeppel et al., Identifying the fundamental units of bacterial diversity: a paradigm shift to incorporate ecology into bacterial systematics. Proceedings of the National Academy of Sciences of the United States of America 105, 2504 (Feb 19, 2008).

8. D. E. Hunt et al., Resource partitioning and sympatric differentiation among closely related bacterioplankton. Science 320, 1081 (May 23, 2008).

9. J. R. Thompson et al., Genotypic diversity within a natural coastal bacterioplankton population. Science 307, 1311 (Feb 25, 2005).

10. S. P. Preheim, S. Timberlake, M. F. Polz, Merging taxonomy with ecological population prediction in a case study of Vibrionaceae. Applied and environmental microbiology 77, 7195 (Oct, 2011).

11. S. P. Preheim et al., Metapopulation structure of Vibrionaceae among coastal marine invertebrates. Environmental microbiology 13, 265 (Jan, 2011).

12. P. R. Burkholder, R. M. Pfister, F. H. Leitz, Production of a pyrrole antibiotic by a marine bacterium. Applied microbiology 14, 649 (Jul, 1966).

13. R. A. Long, F. Azam, Antagonistic interactions among marine pelagic bacteria. Applied and environmental microbiology 67, 4975 (Nov, 2001).

14. Materials and methods are available as supplementary material on Science Online. 
15. B. J. Shapiro et al., Population genomics of early events in the ecological differentiation of bacteria. Science 336, 48 (Apr 6, 2012).

16. J. M. Raaijmakers, I. De Bruijn, O. Nybroe, M. Ongena, Natural functions of lipopeptides from Bacillus and Pseudomonas: more than surfactants and antibiotics. FEMS microbiology reviews 34, 1037 (Nov, 2010).

17. S. F. Altschul, W. Gish, W. Miller, E. W. Myers, D. J. Lipman, Basic local alignment search tool. Journal of molecular biology 215, 403 (Oct 5, 1990).

18. R. A. Long et al., Antagonistic interactions among marine bacteria impede the proliferation of Vibrio cholerae. Applied and environmental microbiology 71, 8531 (Dec, 2005).

19. Acknowledgements: We thank W. Hanage and E. Alm for valuable suggestions. Funding was provided by the Moore Foundation, the Broad Institute's SPARC program, NSF grant DEB 0821391 and the NSF sponsored Woods Hole Center for Oceans and Human Health. Support for O.X.C. was provided by the Netherlands Organisation for Scientific Research. Whole Genome Shotgun projects have been deposited at DDBJ/EMBL/ GenBank under the accessions AJWN00000000, AJYD00000000-AJYZ00000000 and AJZA00000000-AJZQ00000000 (table S4).

Supporting Online Material

Materials and Methods.

Fig. S1 to S5.

Tables S1 to S4.

References. 


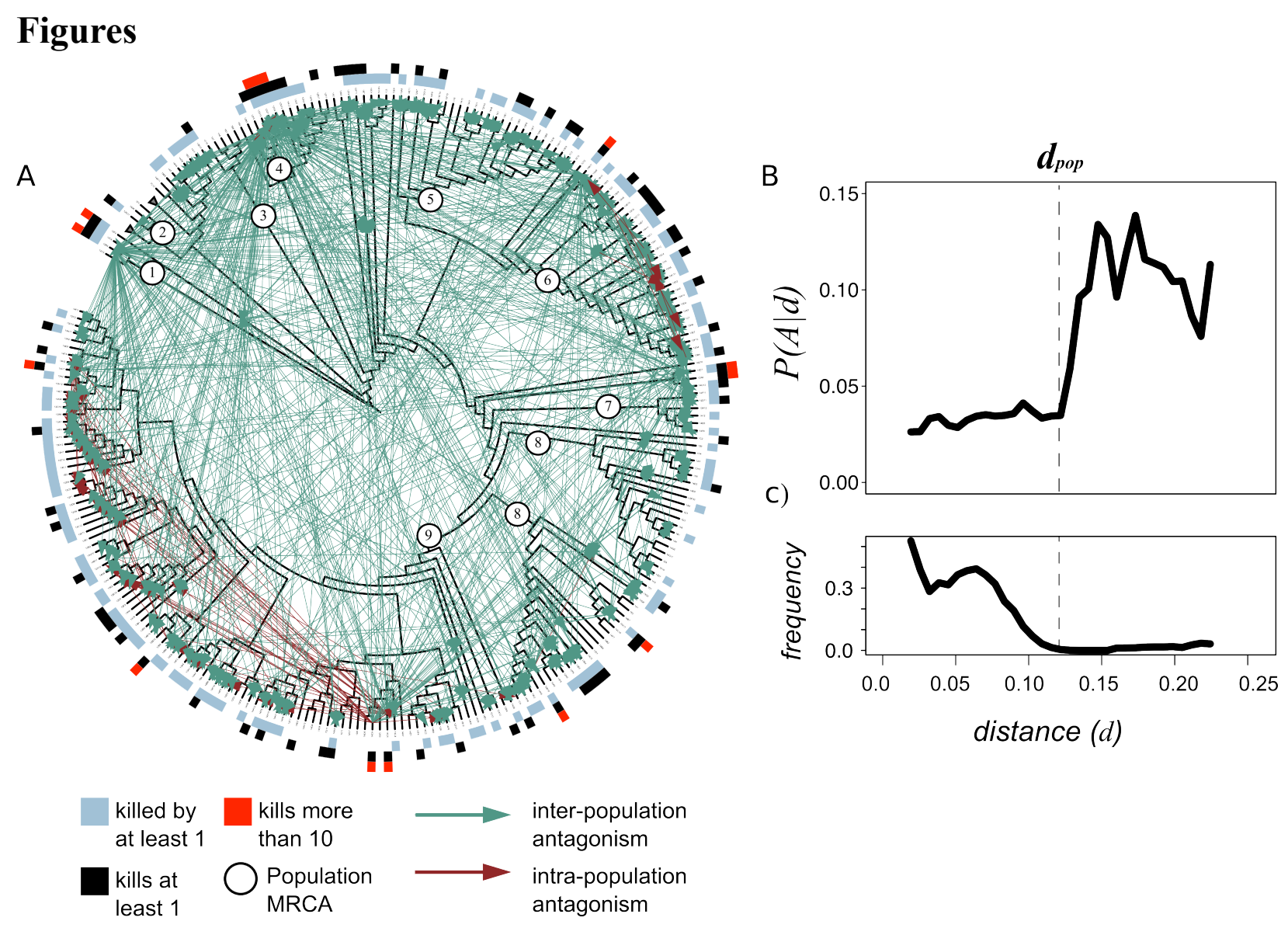

Fig. 1. Distribution of antagonistic interactions in relationship to Vibrio phylogeny and genetic distance. (A) Phylogeny of Vibrio isolates based on 6 housekeeping genes with outer, colored rings highlighting antagonists and sensitive strains. Green arrows connect antagonists to sensitive strains. Circles identify the most recent common ancestor (MRCA) of previously identified ecologically cohesive populations: 1, V. ordalii; 2, V. fischeri; 3, V. breoganii; 4, V. alginolyticus; 5, V. sp. F12; 6, V. crassostreae; 7, V. cyclotrophicus; 8, V. tasmaniensis; 9, V. splendidus. The conditional probability of antagonism as a function of genetic distance, $P(A \mid d)$, shows that antagonistic interactions occur mostly between strains whose genetic distance exceeds a critical threshold. This threshold coincides with the average distance between previously defined populations (dashed line). (C) Frequency distribution of within-population genetic distances, showing that the transition point for $\mathrm{P}(\mathrm{A} \mid d)$ matched the average boundary of populations. 


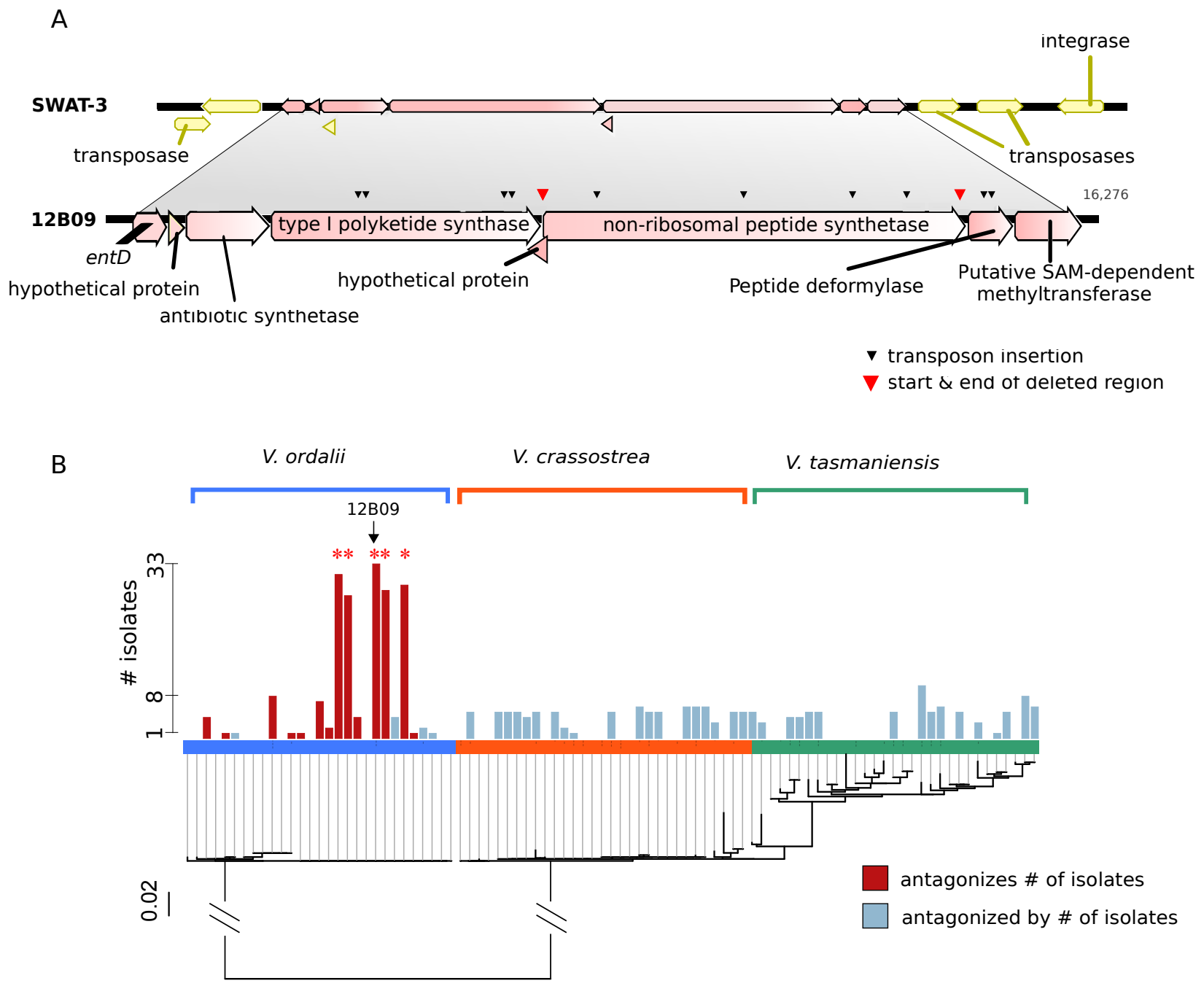

Fig. 2. Antimicrobial peptide cluster and its distribution in the $V$ ordalii population (A) Alignment of NRP cluster from 12B09 showing transposon insertions and knocked-out gene, and homologous cluster from environmental isolate SWAT-3. The figure shows that in SWAT-3, a nearly identical cluster is flanked by transposases and integrases, consistent with the idea that the cluster comprises a mobile element. (B) Antibiotic activity of $V$. ordalii isolates against $V$. ordalii, $V$. crassostreae and $V$. tasmaniensis populations. The phylogeny is based on the $h s p 60$ genetic marker and the bars next to each isolate indicate the number of isolates antagonized (red) and the number of $V$. ordalii isolates that antagonized the isolate (light blue). The red stars mark the five isolates where the NRP gene cluster was detected by PCR. 


\section{Supplementary Online Material}

\section{Ecological populations of bacteria act as socially cohesive units of antibiotic production and resistance}

Otto X. Cordero ${ }^{1 \dagger}$, Hans Wildschutte ${ }^{1 \dagger}$, Benjamin Kirkup ${ }^{1 \dagger}$, Sarah Proeh ${ }^{1}$, Lynn Ngo ${ }^{1}$, Fatima Hussain ${ }^{1}$, Frederique Le Roux ${ }^{2}$, Tracy Mincer ${ }^{3}$ and Martin F. Polz ${ }^{1 *}$

1. Department of Civil and Environmental Engineering, Massachusetts Institute of Technology, Cambridge, MA 02139, USA

2.IFREMER, Laboratoire de Génétique et Pathologie BP 133, 17390 La Tremblade, France

3. Department of Marine Chemistry and Geochemistry, Woods Hole Oceanographic Institution, Woods Hole, Massachusetts 02543, USA

* to whom correspondence should be addressed

$\dagger$ authors contributed equally to this work

This PDF file includes:

Materials and Methods

Figs. S1 to S5

Tables S1 to S4

References 


\section{Materials and Methods}

\section{Antagonism assay and robustness of data.}

Strains were grown overnight 36-48 hours prior to the time of assay in brain heart infusion (Difco) broth $+1.4 \% \mathrm{NaCl}$. To create a lawn of a potentially sensitive strain, $300 \mathrm{uL}$ of the culture was spread on agar plates. Subsequently, potential killers were stamped onto the lawn from 96-well microtiter plates using a replicator. Zones of clearing were recorded between 18 and 24 hours after incubation at $25^{\circ} \mathrm{C}$. To infer expected false positive (FP) and false negative (FN) rates, two strains were selected and their sensitivity tested against all other strains in 5 replicates. True positives are assumed to have replicability $\geq 3 / 5$, and otherwise they are assumed to be true negatives. Using this assumption the expected FP rate is $1.7 \mathrm{e}-4$ and the expected FN rate 0.025 . In addition, a subset of 116 interactions between 130 different strains were re-tested for antagonism using $2 \mathrm{KDa}$ membranes to separate antibiotic producing and sensitive strains. This size-exclusion method allowed screening for antibiotics $<2 \mathrm{KDa}$, and not proteins, which are normally in the range of $>30 \mathrm{KDa}$. Overall, 111 out of the previously scored 116 interactions $(96 \%)$ were replicated, highlighting not only the high replicability of our assay but also that the vast majority of interactions are mediated by small molecules.

\section{Statistical significance of long distance inhibition.}

We used a randomization test to measure the statistical significance of the bias towards long distance killing. We randomized the network of antagonistic interactions keeping the out-degree per node (number of killed strains) constant. This controls simultaneously for the position of killers in the phylogeny as well as for their killing activity. We measured the bias towards long distance killing by counting the number of killed strains at distance $>\boldsymbol{d}_{\boldsymbol{p o p}}$ and found that only 1 out of 1,000 randomized networks had a bias equal or larger than the one observed in the data (non parametric $\mathrm{p}$-value $=0.001$ ).

\section{Mapping of strains to characterized genotypic clusters}

To map isolates to previously characterized populations, we created phylogenetic trees combining all sequences (with and without population assignment). To calculate the confidence of the population mapping, 100 bootstrap replicates where generated with PHYML (1). Sequences were assigned to the best matching population with at least $80 \%$ bootstrap confidence.

\section{Measuring genetic distance.}

To accurately measure evolutionary distances we used a concatenated alignment of 6 housekeeping loci: hsp60, adk, mdh, gyrB, pgi and recA, available for 166 strains. Distances were calculated using the F84 model in the software DNADIST, available in the PHYLIP package (2).

\section{Measuring gene content overlap within populations}

To measure gene content overlap we first clustered protein-coding sequences from 42 sequenced genomes representing 10 different populations using the method defined in OrthoMCL 1.4 (3) with $50 \%$ aminoacid identity cutoff and otherwise default parameters. This resulted in 15,190 
clusters observed in at least one of the 42 strains. We calculated the percentage shared gene content between pairs of genomes using the Jaccard index $|\mathrm{A} \cap \mathrm{B}| /|\mathrm{A} \cup \mathrm{B}|$, where $\mathrm{A}$ and $\mathrm{B}$ are the sets of gene families present in the two genomes being compared.

\section{Identification of antimicrobial peptide cluster.}

The E. coli DH5 $\lambda$ pir donor strain (4) was used to conjugate the mariner-derived transposon vector pSCCAT into $V$. ordalii 12B09. For conjugation, recipient and donor were grown over night at room temperature in $5 \mathrm{ml}$ tryptic soy broth (TSB, Difco) and $5 \mathrm{ml} \mathrm{LB}+150 \mathrm{ul} / \mathrm{ug}$ chloramphenicol $(\mathrm{Cm})+250 \mathrm{uM}$ diaminopimelic acid (DAP), respectively. Cells of each type where harvested, mixed and plated as a mating spot on TSB plates +250 uM DAP. Mating spots were incubated overnight at room temperature and suspended in $20 \mathrm{ml} \mathrm{TSB} .100 \mathrm{ul}$ aliquots were spread on TSB plates $+12.5 \mathrm{ug} / \mathrm{ml} \mathrm{Cm}$ and grown overnight at room temperature. 12B09 mutants were replica plated onto the sensitive strain ZF91 ( $V$. crassostreae) and screened for loss of antagonism phenotype. Transposon insertion sites were identified by bubble PCR (Polymerase Chain Reaction). A deletion mutant was constructed using a suicide vector for construction of Vibrio gene deletion mutants.

\section{Conjugation and Transposon Mutageneis}

The mariner derived transposon vector pSC-CAT was constructed from pSC180 by exchanging the kanamycin gene with the chloramphenicol acetyl transferease gene. The E. coli DH5 $\lambda$ pir donor strain was used to conjugate pSC-CAT into V. ordalii 12B09 (4). For conjugation, the donor and recipient were grown overnight at $37^{\circ} \mathrm{C}$ in $5 \mathrm{ml} \mathrm{LB}+150 \mathrm{ul} / \mathrm{ug}$ chloramphenicol $(\mathrm{Cm})$ $+250 \mathrm{uM}$ diaminopimelic acid (DAP) and at $21^{\circ} \mathrm{C}$ in $5 \mathrm{ml}$ tryptic soy broth (TSB), respectively. One $\mathrm{ml}$ of each cell type was centrifuged for 5 minutes at 13,000 rpm and resuspended in $1 \mathrm{ml}$ TSB. $100 \mathrm{ul}$ of the recipient and donor was combined, centrifuged for 5 minutes at 13,000 rpm, resuspended in $10 \mathrm{ul} \mathrm{TSB}$, spotted onto TSB $+250 \mathrm{uM}$ DAP and incubated overnight at room temperature. The spot was suspended in $20 \mathrm{ml} \mathrm{TSB}$. 100 ul aliquots were spread plated on TSB + $12.5 \mathrm{ug} / \mathrm{ml} \mathrm{Cm}$ and grown overnight at room temperature. 12B09 mutants were replica plated to the sensitive strain ZF91 and screened for loss of antagonism phenotype. Transposon insertion sites were identified by bubble PCR.

\section{DNA isolation and bubble PCR}

Mutants with loss of antagonism phenotype were grown in $3 \mathrm{ml} \mathrm{TSB}+12.5 \mathrm{ug} / \mathrm{ml} \mathrm{Cm}$ overnight at room temperature. For genomic DNA isolation, centrifugation of $1.5 \mathrm{ml}$ cells was performed and pellets were resuspended in $300 \mathrm{ul}$ cell lysis solution (Qiagen, catalog \# 158908). After incubation at $80^{\circ} \mathrm{C}$ for 5 minutes, $1.5 \mu \mathrm{l}$ of $4 \mathrm{mg} / \mathrm{ml}$ of RNase A was added and incubated at $37^{\circ} \mathrm{C}$ for 30 minutes. $100 \mu \mathrm{l}$ of protein precipitation solution (Qiagen, catalog \# 158912) was added and vortex. After centrifugation, $300 \mu \mathrm{l}$ isopropyl alcohol was added to the supernatant. DNA was pelleted by centrifugation. The pellet was rinsed with $70 \%$ ethanol, dried and resuspended in $100 \mu 1$ DNA hydration solution (Qiagen catalogue \# 158916).

Bubble PCR (BPCR) was used to identify transposon insertion in the genome of mutants showing loss of antagonism phenotype. Two $\mu \mathrm{g}$ of genomic DNA was digested with restriction 
enzyme PvuII, SacI, SmaI, or SspI. Digested DNA was ligated to $4 \mu \mathrm{M}$ of annealed bubble PCR primers BPHI and BPHII using T4 DNA ligase. BPCR I was performed using 2 ul of digested DNA and $5 \mathrm{uM}$ primers 224 and pSCCAT2067 which anneal to the ligated primer BPHI and the pSC-CAT vector, respectively. BPCRI was performed at $92^{\circ} \mathrm{C}$ denaturing for $10 \mathrm{~s}, 60^{\circ} \mathrm{C}$ annealing for $60 \mathrm{~s}$, and elongation at $72^{\circ} \mathrm{C}$ for $90 \mathrm{~s}$ and repeated 19 times. BPCR I products were diluted 1:25 and $2 \mu \mathrm{l}$ of DNA was used to performed BPCR II with $5 \mu \mathrm{m}$ primers 224 and pSCCAT2036. BPCR reaction II was performed at $92^{\circ} \mathrm{C}$ denaturing for $10 \mathrm{~s}, 55^{\circ} \mathrm{C}$ annealing for $30 \mathrm{~s}, 72^{\circ} \mathrm{C}$ elongation for $90 \mathrm{~s}$ and was repeated 34 times. BPCR II products were sequenced by GENEWIZ, Inc using primers 224, pSCCAT2067, and pSCCAT3036.

\section{Construction of pJC4}

Plasmid pJC4 was constructed from pMW91 (4) and used to create Vibrio gene deletion mutants. pJC4 is a R6K based suicide vector containing $s a c B$ gene for counter-selection of allelic exchange. Briefly, pMW91 was digested with $S c a$ I to disrupt the beta lactamase gene. The chloramphenicol acetyl transferease gene was amplified from pACYC184 and cloned into the ScaI site giving pJC4.

\section{Deletion of non-ribosomal peptide (NRP) biosynthesis gene}

The NRP gene was targeted for deletion by creating a fusion PCR fragment that lacked the NRP gene as shown in (5). Briefly, 750 base pairs upstream and downstream of the NRP gene were amplified using the primer pairs 12B09 2900F - 12B09 3683R and 12B09 9848F - 12B09 10593R, respectively. Primers 12B09 2900F and 12B09 10593R have a complementary tail so their respective amplicons can anneal and produce a single template generating a fusion $\triangle \mathrm{NRP}$ PCR product. For fusion PCR, the $1.5 \mathrm{~kb} \triangle \mathrm{NRP}$ product was generated using the $12 \mathrm{~B} 092900 \mathrm{~F}$ and 12B09 10593R primers with one ul of the up- and downstream products as the DNA template. The fusion PCR product was digested with SpeI and cloned into the suicide plasmid pJC4 resulting in pHW44. pHW44 was conjugated to 12B09 as described above. Homologous recombination between fusion PCR product and the 12B09 chromosome resulted in chloramphenicol resistant transconjugants. Transconjugants were grown overnight in TSB + $2 \% \mathrm{NaCl}$. A serial dilution was performed on LB plates without salt $+5 \%$ sucrose. Loss of the NRP gene was confirmed by sequencing using primers 12B09 2900F and 12B09 10593R.

Table S1. Primers used in this study.

\begin{tabular}{|l|l|}
\hline Primer & Sequence \\
\hline BPHI & $\begin{array}{l}\text { 5' CAA GGA GAGGACGCT GTC TGT CGA AGG TAA GGA ACG GAC GAG AGA AGG GAG } \\
\text { AG 3' }\end{array}$ \\
\hline BPHII & $\begin{array}{l}\text { 5'CTC TCC CTT CTC GAA TCG TAA CCG TTC GTA CGA GAA TCG CTG TCC TCT CCT TG } \\
\text { 3' }\end{array}$ \\
\hline 224 & 5' CGA ATC GTA ACC GTT CGT ACG AGA ATC GCT 3' \\
\hline pSCCAT2067 & 5' GGC CGA AAT CGG CAA AAT CC 3' \\
\hline pSCCAT2036 & 5' AAA GAA TAG ACC GAG ATA GG 3' \\
\hline 12B09 2900F & 5' GGA CTA GTA CGC GAC ACT CAA AGC CAG C 3' \\
\hline
\end{tabular}


12B09 3683R 5' GGT GGT CCT CAA AGA AAT TAA CGA GTT CTA AAT ATT CGA CTA AGT G 3' 12B09 9848F 5' TCG TTA ATT TCT TTG AGG ACC ACC AAA CAA CAA TGG CTA TCA GAC C 3' 12B09 10593R 5' GGA CTA GTT ACA AAC CCG GAC CGC AGG C 3'

\section{Extraction of antibiotic from Vibrio ordalii 12B09}

Strains of 12B09 (either the wt or HW44) were inoculated from overnight starter cultures and grown in 1L of Difco 2216 marine broth in a $2.8 \mathrm{~L}$ Fernbach flask with 150 RPM shaking at 25 $\mathrm{C}^{\circ}$ for 24 hours. Subsequently, $20 \mathrm{~g}$ of sterile XAD-7 resin was added with shaking at $25 \mathrm{C}^{\circ}$ for 16 hours. The XAD-7 resin was harvested by filtration through glass wool and rinsed with $1 \mathrm{~L}$ of distilled water and dried under vacuum filtration. The resin was eluted thrice with $100 \mathrm{~mL}$ of optime grade methanol (Fisher Scientific, Valencia CA.), which was subsequently reduced to dryness using rotary evaporation. Crude extracts were prepared by resuspension in DMSO to a final concentration of $50 \mathrm{mg} / \mathrm{mL}$. These were filtered through a $0.45 \mu \mathrm{m}$ glass fiber filter and stored at $-20 \mathrm{C}^{\circ}$ until further analyses. Crude bioactivities were compared using quantitative dilution and employing a disk-diffusion method measuring inhibition zone on solid medium as described in methods. The crude extract was found to account for $100 \%$ of the culture activity based on cell counts of cultures of 12B09wt. Biological testing was performed in biological triplicates in the testing of 12B09-HW44.

\section{Large-scale normal phase flash chromatography}

Crude extract paste material from 10 replicate $1 \mathrm{~L}$ cultures of 12B09wt was obtained as outlined above and resuspended in $20 \mathrm{~mL}$ 1:1:1 trimethylpentane (TMP):ethylacetate:methanol. The crude resuspension was mixed with $50 \mathrm{~g}$ of silica gel mesh 230-400 (Whatman, Piscataway, NJ), dried using rotary evaporation and loaded onto a $300 \mathrm{ml}$ bed volume of silica gel in a $600 \mathrm{ml}$ vacuum funnel. Solvents of increasing polarity were added and collected as separate fractions of one bed volume of TMP, 1:1 TMP:ethylacetate, ethylacetate, 1:1 ethylacetate:acetone, acetone, and methanol. All fractions were evaporated to dryness and tested by a disk-diffusion assay. The acetone fraction was found to account for $100 \%$ of the antibiotic activity. 


\section{Supporting Figures}

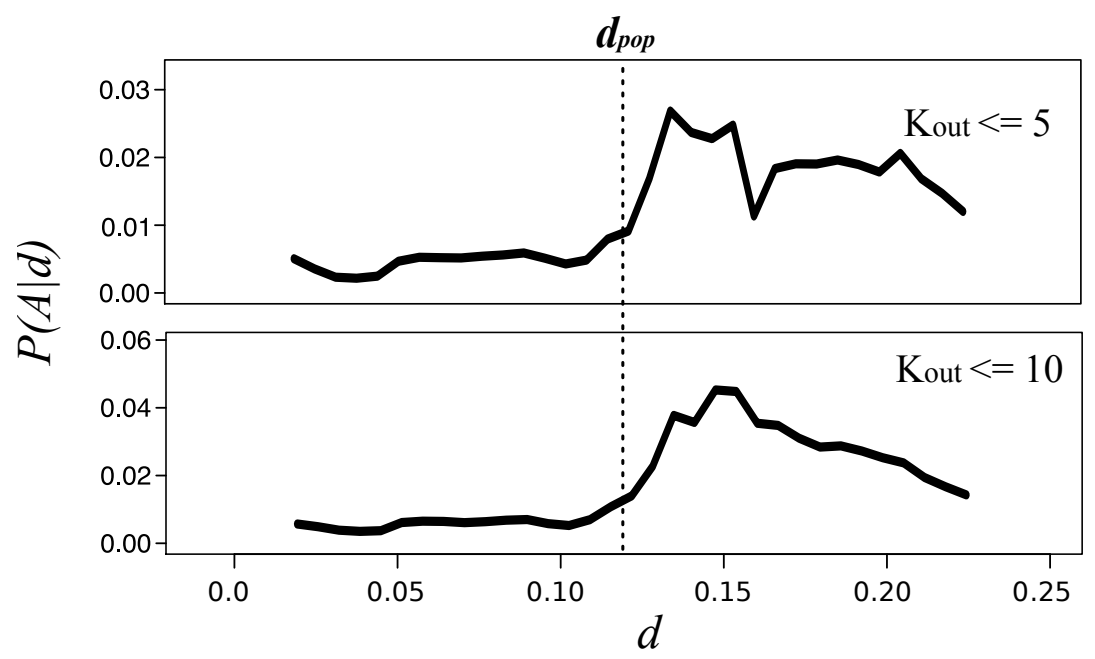

Figure S1. Bias towards long distance antagonism was not driven by broad-range killers. $\mathrm{P}(\mathrm{A} \mid d)$ represents the probability of antagonism given the genetic distance, $d$, and $\boldsymbol{d}_{\boldsymbol{p} \text { op }}$ marks the boundary between ecological populations as described in the main text. In the upper panel (Kout $\leq 5$ ), strains inhibiting more than 5 other strains have been removed from the network along with their interactions. In the lower panel (Kout $\leq 10$ ), the maximum allowed number of inhibited strains is 10. The figures show that the trend depicted in Figure 1 of the main text holds even when focusing on highly specific antagonisms. 

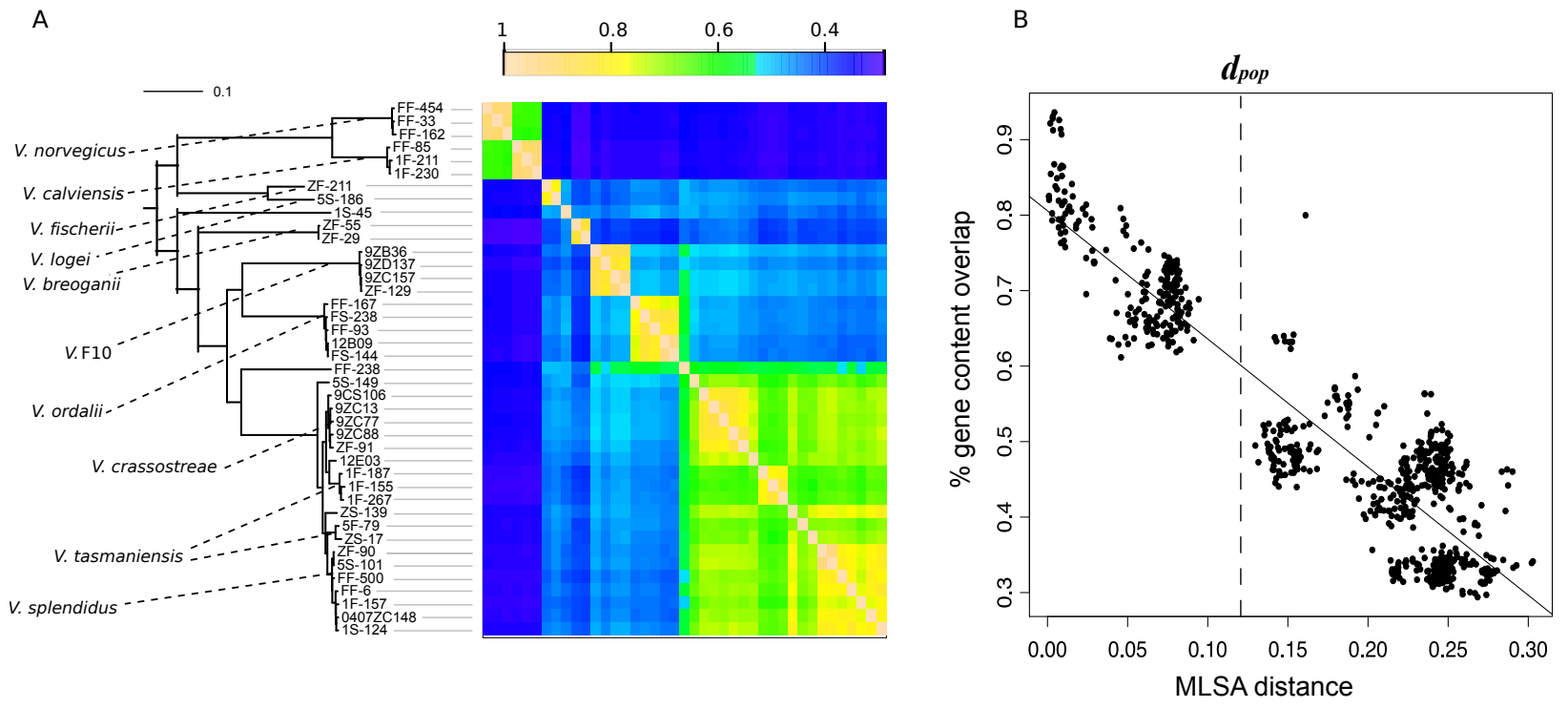

Figure S2. High variability in gene content despite overall coherence of phylogenomic signal. A) Vibrio phylogeny of 41 sequenced genomes from 10 populations based on 40 gene families present in $97.5 \%$ of the sequenced strains. Populations form tight clusters based on housekeeping genes and can also be clustered based on gene content. B) The figure shows the overlap in gene content as a function of the genetic distance calculated from 6 housekeeping genes as described in the main text. The average gene content overlap is $72 \%$ below $\boldsymbol{d}_{p o p}$. Each data point represents pairwise comparisons between the 41 sequenced strains. 


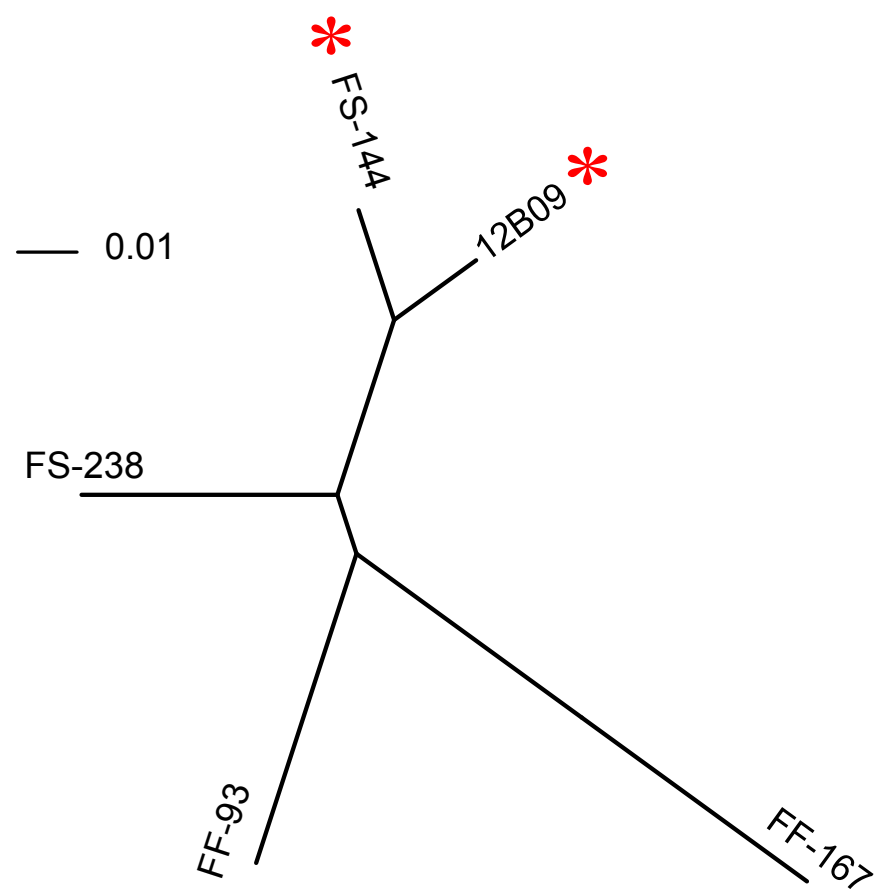

Figure S3. Whole genome tree of five sequenced $V$. ordalii strains shows that super-killers 12B09 and FS-144 have recently diverged, suggesting that the acquisition of the antimicrobial peptide was a single recent event in their common ancestor. Whole genome alignment tree were generated with Mauve (6). Red asterisks indicate super-killer strains carrying the antibiotic cluster. 
DAD1 C, Sig=210,8 Ref $=360,100$ (EXTRACT000063.D)

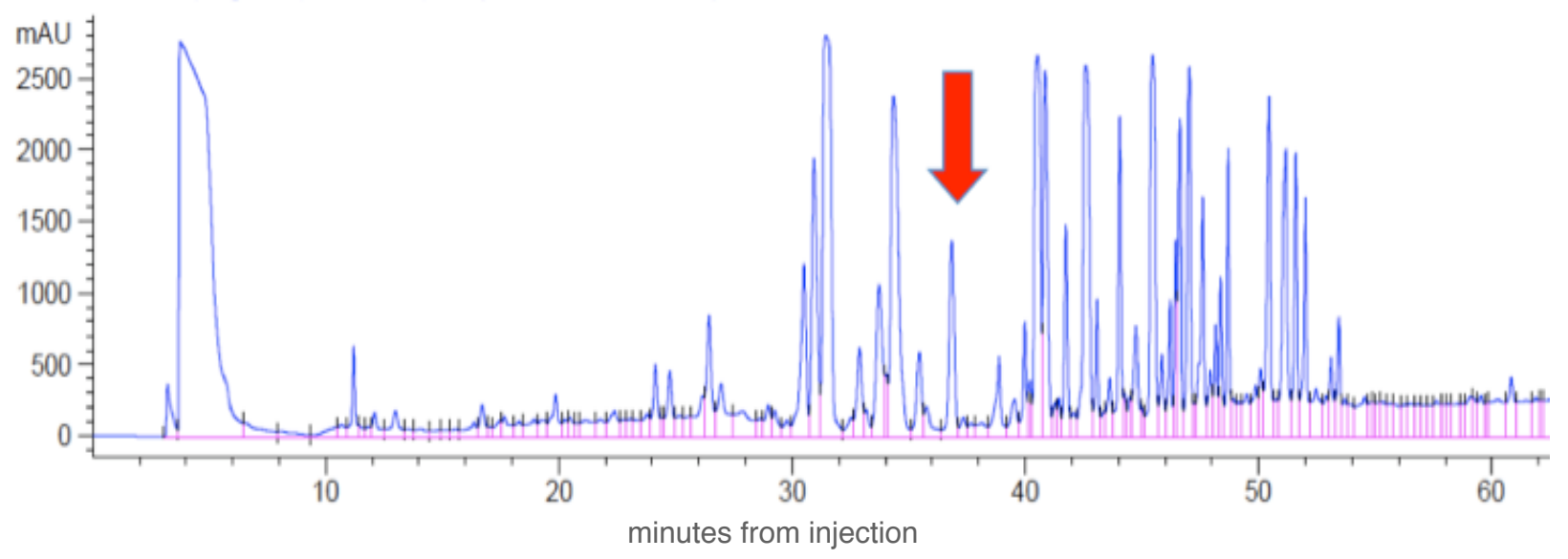

Figure S4. Identification of active fraction from 12B09 by chromatography. The figure shows the reverse-phase HPLC-Diode array detection (at 210nm) chromatogram of a flash chromatography $(100 \%$ acetone elute from silica gel) run with a gradient of $0-30 \%$ acetonitrile:water, $0.4 \mathrm{~mL} / \mathrm{min}$. The compound marked by red arrow eluting at $37 \mathrm{~min}(18 \%$ acetonitrile:water) was responsible for $100 \%$ of the antibiotic activity in the $12 \mathrm{~B} 09$ antibiotic assay. 


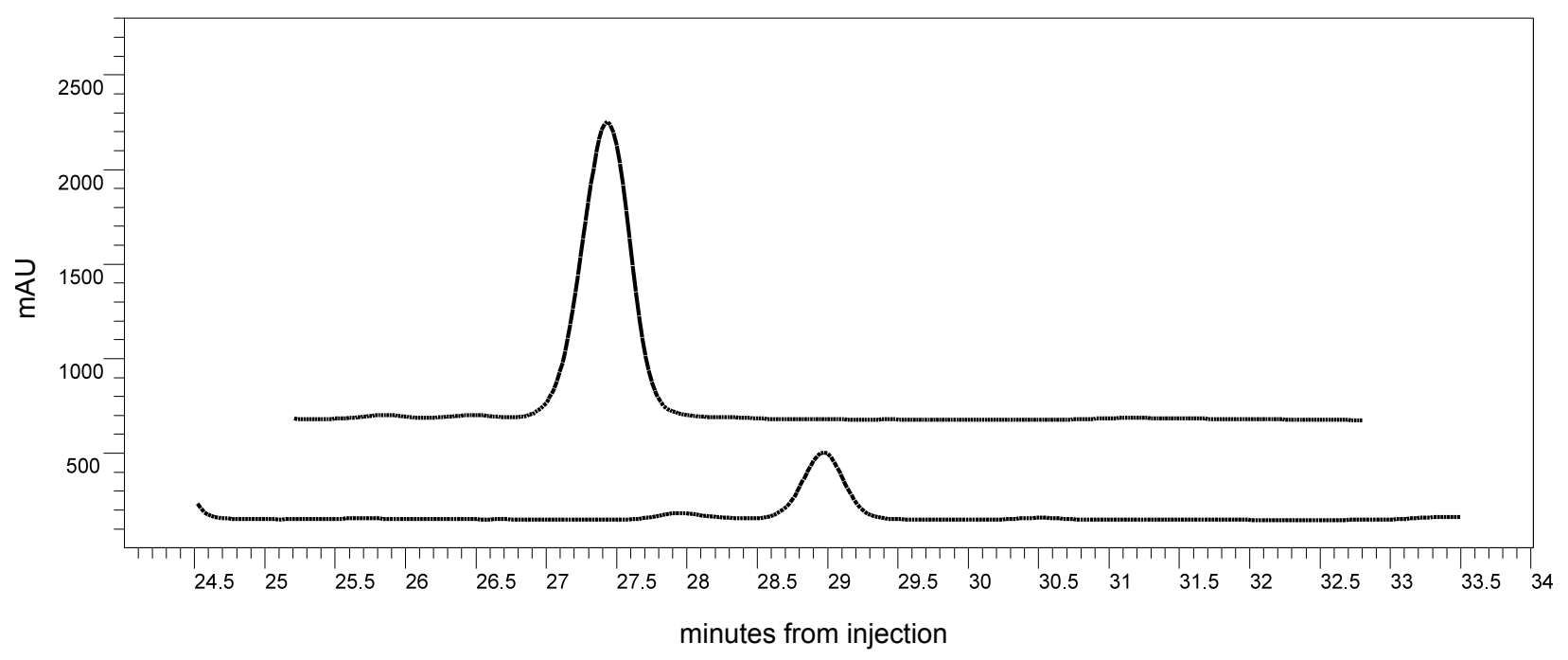

Figure S5: Lack of active compound in knock-out mutant 12B09-HW44. The figure shows a reverse-phase HPLC-DAD analysis (monitored at $300 \mathrm{~nm}$ ) employing a 20\% acetonitrile:water isocratic solvent system at a at $0.4 \mathrm{~mL} / \mathrm{min}$ flow rate to compare the transposon knock-out mutant HW44 (bottom trace) with 12B09 wt (top trace). The peak at 27.4 minutes accounts for $100 \%$ of antibiotic activity and is completely absent in the HW44 trace. The appearance of the small peak at the 29 minute retention time is a malformed product which was found to have no antibiotic activity by peak-based collection and bioassay. 
Table S2. List of 185 isolates from the all-against-all network with their corresponding outdegree (number of isolates antagonized) and in-degree (number of isolates that antagonize it).

\begin{tabular}{|c|c|c|}
\hline isolates name & out-degree & in-degree \\
\hline $12 \mathrm{~A} 11$ & 0 & 1 \\
\hline 13B11 & 77 & 5 \\
\hline $12 \mathrm{CO} 2$ & 0 & 3 \\
\hline $12 \mathrm{~A} 08$ & 2 & 2 \\
\hline $12 \mathrm{G} 02$ & 33 & 11 \\
\hline $1 \mathrm{CO}$ & 2 & 0 \\
\hline $12 \mathrm{G} 06$ & 0 & 6 \\
\hline $1 \mathrm{C02}$ & 3 & 0 \\
\hline $13 \mathrm{~A} 01$ & 0 & 8 \\
\hline $13 \mathrm{~A} 11$ & 1 & 5 \\
\hline $14 \mathrm{C} 02$ & 0 & 1 \\
\hline 14B06 & 1 & 4 \\
\hline 13E02 & 0 & 7 \\
\hline $13 F 02$ & 0 & 7 \\
\hline $14 \mathrm{HO} 08$ & 0 & 2 \\
\hline $1 \mathrm{~A} 12$ & 0 & 4 \\
\hline 13B10 & 3 & 6 \\
\hline $14 \mathrm{C08}$ & 2 & 1 \\
\hline $12 \mathrm{~F} 11$ & 1 & 15 \\
\hline $12 \mathrm{G} 11$ & 5 & 2 \\
\hline 13E09 & 1 & 0 \\
\hline 1B09 & 0 & 5 \\
\hline $1 \mathrm{~B} 01$ & 0 & 4 \\
\hline $1 \mathrm{~B} 11$ & 0 & 6 \\
\hline $12 \mathrm{G} 04$ & 0 & 9 \\
\hline $12 \mathrm{G} 12$ & 107 & 1 \\
\hline $12 \mathrm{G} 08$ & 0 & 7 \\
\hline 12B11 & 3 & 0 \\
\hline 12B04 & 2 & 6 \\
\hline 13B03 & 0 & 1 \\
\hline 13D07 & 0 & 4 \\
\hline $12 \mathrm{~A} 10$ & 8 & 1 \\
\hline $12 \mathrm{HO} 4$ & 2 & 4 \\
\hline 13E05 & 1 & 6 \\
\hline $13 \mathrm{H} 05$ & 0 & 3 \\
\hline $12 \mathrm{E} 12$ & 1 & 4 \\
\hline 14D03 & 0 & 5 \\
\hline 14C03 & 1 & 4 \\
\hline $14 \mathrm{~B} 10$ & 0 & 4 \\
\hline
\end{tabular}




\begin{tabular}{|c|c|c|}
\hline isolates name & out-degree & in-degree \\
\hline 14D12 & 0 & 11 \\
\hline $14 \mathrm{H} 05$ & 0 & 4 \\
\hline $14 \mathrm{G} 04$ & 0 & 6 \\
\hline 14D07 & 44 & 2 \\
\hline $14 \mathrm{~A} 03$ & 1 & 5 \\
\hline $1 \mathrm{CO3}$ & 0 & 8 \\
\hline $1 \mathrm{C09}$ & 1 & 4 \\
\hline $13 \mathrm{~A} 03$ & 0 & 9 \\
\hline $13 \mathrm{C} 01$ & 0 & 4 \\
\hline 12D12 & 1 & 2 \\
\hline 12B05 & 10 & 0 \\
\hline $12 \mathrm{H} 10$ & 1 & 0 \\
\hline $13 \mathrm{G} 02$ & 2 & 6 \\
\hline $12 \mathrm{~A} 09$ & 4 & 0 \\
\hline 12B10 & 18 & 3 \\
\hline $13 \mathrm{H} 06$ & 0 & 3 \\
\hline $12 \mathrm{~F} 12$ & 0 & 9 \\
\hline $14 \mathrm{~F} 08$ & 0 & 3 \\
\hline $14 \mathrm{~F} 05$ & 0 & 4 \\
\hline 14E05 & 1 & 3 \\
\hline $14 \mathrm{G} 03$ & 0 & 4 \\
\hline 14E06 & 0 & 6 \\
\hline $14 \mathrm{G} 09$ & 0 & 3 \\
\hline $12 \mathrm{~F} 08$ & 12 & 9 \\
\hline $12 \mathrm{~F} 03$ & 3 & 10 \\
\hline $12 \mathrm{E} 06$ & 7 & 7 \\
\hline $12 \mathrm{C} 11$ & 1 & 5 \\
\hline 13E07 & 1 & 0 \\
\hline $14 \mathrm{E} 02$ & 4 & 0 \\
\hline $1 \mathrm{C} 01$ & 1 & 2 \\
\hline 1D01 & 4 & 1 \\
\hline $12 \mathrm{~F} 05$ & 6 & 0 \\
\hline $1 \mathrm{~A} 05$ & 0 & 1 \\
\hline $14 \mathrm{H} 11$ & 0 & 5 \\
\hline $13 \mathrm{C} 05$ & 1 & 3 \\
\hline $12 \mathrm{H} 09$ & 0 & 6 \\
\hline $13 \mathrm{~A} 10$ & 0 & 14 \\
\hline 12D11 & 1 & 4 \\
\hline $12 \mathrm{CO5}$ & 0 & 3 \\
\hline 12D09 & 0 & 4 \\
\hline 14E01 & 0 & 3 \\
\hline $14 \mathrm{~A} 06$ & 1 & 4 \\
\hline
\end{tabular}




\begin{tabular}{|c|c|c|}
\hline isolates name & out-degree & in-degree \\
\hline $13 \mathrm{G} 08$ & 0 & 4 \\
\hline 1D08 & 0 & 4 \\
\hline $13 G 12$ & 0 & 3 \\
\hline $14 \mathrm{C} 04$ & 55 & 0 \\
\hline $14 \mathrm{E} 03$ & 0 & 3 \\
\hline $12 \mathrm{G} 09$ & 0 & 6 \\
\hline $13 \mathrm{H} 11$ & 0 & 4 \\
\hline 13D01 & 0 & 1 \\
\hline $1 \mathrm{E} 06$ & 0 & 3 \\
\hline 1D10 & 0 & 4 \\
\hline 14B11 & 0 & 3 \\
\hline 12D07 & 0 & 6 \\
\hline $14 \mathrm{H} 09$ & 0 & 3 \\
\hline $14 \mathrm{G} 06$ & 0 & 11 \\
\hline 1A11 & 0 & 5 \\
\hline 14D09 & 0 & 4 \\
\hline $14 \mathrm{~B} 12$ & 0 & 9 \\
\hline $12 \mathrm{H} 05$ & 0 & 7 \\
\hline $14 \mathrm{C} 01$ & 0 & 1 \\
\hline 13D12 & 0 & 7 \\
\hline 13D09 & 1 & 8 \\
\hline 1D02 & 0 & 3 \\
\hline 13E06 & 0 & 18 \\
\hline 12E04 & 1 & 0 \\
\hline $13 \mathrm{C} 04$ & 0 & 4 \\
\hline $12 \mathrm{H} 11$ & 3 & 0 \\
\hline $12 \mathrm{~A} 01$ & 4 & 14 \\
\hline $12 \mathrm{CO9}$ & 2 & 0 \\
\hline $13 \mathrm{G} 10$ & 0 & 1 \\
\hline $1 \mathrm{~B} 07$ & 1 & 8 \\
\hline $14 \mathrm{~A} 07$ & 0 & 7 \\
\hline 12D08 & 4 & 1 \\
\hline $13 \mathrm{C} 12$ & 0 & 3 \\
\hline $14 \mathrm{C} 10$ & 2 & 0 \\
\hline 13B01 & 1 & 7 \\
\hline $14 \mathrm{H} 02$ & 0 & 5 \\
\hline $14 \mathrm{C} 11$ & 0 & 15 \\
\hline $1 \mathrm{~B} 03$ & 0 & 5 \\
\hline 13E04 & 1 & 6 \\
\hline $13 \mathrm{~F} 08$ & 0 & 3 \\
\hline $12 \mathrm{~A} 06$ & 18 & 0 \\
\hline 1A09 & 0 & 1 \\
\hline
\end{tabular}




\begin{tabular}{|c|c|c|}
\hline isolates name & out-degree & in-degree \\
\hline 14B08 & 0 & 6 \\
\hline $12 \mathrm{G} 05$ & 0 & 10 \\
\hline $12 \mathrm{G} 01$ & 42 & 28 \\
\hline $12 \mathrm{G} 07$ & 1 & 6 \\
\hline $12 \mathrm{G} 03$ & 0 & 2 \\
\hline 12B09 & 110 & 3 \\
\hline $12 \mathrm{~F} 02$ & 1 & 4 \\
\hline $12 \mathrm{E} 02$ & 1 & 6 \\
\hline $14 \mathrm{~F} 04$ & 7 & 0 \\
\hline $1 \mathrm{~A} 03$ & 0 & 6 \\
\hline $1 \mathrm{C} 07$ & 0 & 11 \\
\hline $1 \mathrm{~B} 02$ & 0 & 5 \\
\hline 13A04 & 0 & 3 \\
\hline $13 \mathrm{~F} 04$ & 1 & 0 \\
\hline $1 \mathrm{~B} 10$ & 0 & 9 \\
\hline $14 \mathrm{~A} 11$ & 13 & 5 \\
\hline $14 \mathrm{~F} 06$ & 0 & 3 \\
\hline $14 \mathrm{C} 05$ & 0 & 2 \\
\hline $13 \mathrm{H} 04$ & 1 & 4 \\
\hline $14 \mathrm{~A} 10$ & 1 & 1 \\
\hline $14 \mathrm{C} 06$ & 1 & 1 \\
\hline $12 \mathrm{E} 10$ & 0 & 4 \\
\hline 14E04 & 2 & 6 \\
\hline 13B07 & 0 & 10 \\
\hline $12 \mathrm{H} 02$ & 0 & 4 \\
\hline $13 \mathrm{~A} 02$ & 0 & 2 \\
\hline $14 \mathrm{G} 12$ & 5 & 1 \\
\hline $13 \mathrm{E} 10$ & 4 & 0 \\
\hline $12 \mathrm{G} 10$ & 0 & 6 \\
\hline $14 \mathrm{~F} 11$ & 0 & 3 \\
\hline $13 \mathrm{~A} 08$ & 0 & 9 \\
\hline $1 \mathrm{E} 01$ & 0 & 5 \\
\hline 1D09 & 0 & 7 \\
\hline 12D05 & 2 & 0 \\
\hline $13 \mathrm{H} 12$ & 0 & 3 \\
\hline $13 \mathrm{H} 02$ & 0 & 2 \\
\hline $13 \mathrm{~B} 12$ & 5 & 9 \\
\hline $14 \mathrm{~F} 09$ & 0 & 3 \\
\hline 1D07 & 0 & 7 \\
\hline $12 \mathrm{~F} 04$ & 31 & 5 \\
\hline $14 \mathrm{~F} 10$ & 0 & 4 \\
\hline 14E07 & 1 & 4 \\
\hline
\end{tabular}




\begin{tabular}{|c|c|c|}
\hline isolates name & out-degree & in-degree \\
\hline $14 \mathrm{C} 07$ & 38 & 0 \\
\hline 13G07 & 0 & 6 \\
\hline $12 \mathrm{H} 01$ & 0 & 5 \\
\hline 14C09 & 61 & 0 \\
\hline $14 \mathrm{~A} 04$ & 0 & 5 \\
\hline 1C05 & 0 & 1 \\
\hline $13 F 11$ & 0 & 2 \\
\hline 12B08 & 17 & 0 \\
\hline 13D11 & 1 & 1 \\
\hline $14 \mathrm{H06}$ & 0 & 9 \\
\hline $14 \mathrm{~A} 12$ & 1 & 0 \\
\hline 12B02 & 0 & 12 \\
\hline 13D03 & 2 & $\underline{0}$ \\
\hline $13 \mathrm{C} 10$ & 1 & 2 \\
\hline $7 \mathrm{G} 11$ & 4 & $\underline{0}$ \\
\hline 1D12 & 0 & 3 \\
\hline $12 \mathrm{~F} 10$ & 0 & 11 \\
\hline 12F06 & 1 & 9 \\
\hline $12 \mathrm{E} 11$ & 0 & 7 \\
\hline 12E05 & 1 & 7 \\
\hline
\end{tabular}


Table S3. List of 91 isolates from the V. ordalii-tasmaniensis-crassostreae network with their corresponding out-degree (number of isolates antagonized) and in-degree (number of isolates that antagonize it). The field "in-degree (from ordalii)" shows the number of ordalii isolates that contribute to the total in-degree (Fig 2 of the main text).

\begin{tabular}{|c|c|c|c|c|}
\hline isolate name & population & out-degree & in-degree & $\begin{array}{c}\text { in-degree (from } \\
\text { ordalii) }\end{array}$ \\
\hline FAL5122 & V. crassostreae & 0 & 5 & 5 \\
\hline FALZ15 & V. crassostreae & 0 & 7 & 5 \\
\hline FALZ91 & V. crassostreae & 0 & 8 & 5 \\
\hline $12 \mathrm{~F} 10$ & V. crassostreae & 0 & 8 & 6 \\
\hline $14 \mathrm{~A} 01$ & V. crassostreae & 10 & 6 & 6 \\
\hline FAL5161 & V. crassostreae & 0 & 8 & 5 \\
\hline FALZ17 & V. crassostreae & 0 & 5 & 2 \\
\hline FAL1165 & V. crassostreae & 0 & 7 & 6 \\
\hline $12 \mathrm{CO} 04$ & V. crassostreae & 9 & 1 & 1 \\
\hline FALZ8 & V. crassostreae & 0 & 3 & 0 \\
\hline 13E10 & V. crassostreae & 2 & 5 & 5 \\
\hline 14E07 & V. crassostreae & 0 & 2 & 0 \\
\hline FALZ219 & V. crassostreae & 0 & 5 & 5 \\
\hline FALZ269 & V. crassostreae & 0 & 7 & 6 \\
\hline $12 \mathrm{~A} 08$ & V. crassostreae & 0 & 3 & 0 \\
\hline $13 \mathrm{H} 05$ & V. crassostreae & 0 & 1 & 0 \\
\hline 12B04 & V. crassostreae & 0 & 6 & 5 \\
\hline FALF372 & V. crassostreae & 0 & 4 & 4 \\
\hline FALZ49 & V. crassostreae & 0 & 5 & 5 \\
\hline 14F03 & V. crassostreae & 0 & 5 & 5 \\
\hline 13D10 & V. crassostreae & 0 & 6 & 5 \\
\hline SPR1297 & V. crassostreae & 0 & 5 & 5 \\
\hline FALZ33 & V. crassostreae & 0 & 1 & 0 \\
\hline FALZ100 & V. crassostreae & 0 & 5 & 5 \\
\hline $13 \mathrm{G} 12$ & V. crassostreae & 0 & 0 & 0 \\
\hline $14 \mathrm{C} 11$ & V. crassostreae & 0 & 0 & 0 \\
\hline FAL1255 & V. crassostreae & 0 & 0 & 0 \\
\hline FALF58 & V. crassostreae & 0 & 0 & 0 \\
\hline FALZ113 & V. crassostreae & 0 & 0 & 0 \\
\hline $12 \mathrm{E} 02$ & V. crassostreae & 0 & 0 & 0 \\
\hline $13 \mathrm{H} 03$ & V. crassostreae & 0 & 0 & 0 \\
\hline SPRF143 & V. ordalii & 28 & 0 & 0 \\
\hline SPR1143 & V. ordalii & 4 & 0 & 0 \\
\hline FALF159 & V. ordalii & 4 & 0 & 0 \\
\hline SPR1257 & V. ordalii & 7 & 0 & 0 \\
\hline FALF68 & V. ordalii & 0 & 2 & 2 \\
\hline
\end{tabular}




\begin{tabular}{|c|c|c|c|c|}
\hline isolate name & population & out-degree & in-degree & $\begin{array}{c}\text { in-degree (from } \\
\text { ordalii) }\end{array}$ \\
\hline FALF2 & V. ordalii & 8 & 0 & 0 \\
\hline FALF197 & V. ordalii & 0 & 1 & 1 \\
\hline FALF236 & V. ordalii & 1 & 0 & 0 \\
\hline SPRF219 & V. ordalii & 1 & 0 & 0 \\
\hline SPRF203 & V. ordalii & 0 & 1 & 1 \\
\hline FAL1128 & V. ordalii & 1 & 0 & 0 \\
\hline FALF222 & V. ordalii & 2 & 0 & 0 \\
\hline FALF31 & V. ordalii & 1 & 0 & 0 \\
\hline SPRF144 & V. ordalii & 27 & 0 & 0 \\
\hline FALF443 & V. ordalii & 29 & 0 & 0 \\
\hline SPRF148 & V. ordalii & 0 & 4 & 4 \\
\hline FALF495 & V. ordalii & 31 & 0 & 0 \\
\hline 12B09 & V. ordalii & 33 & 0 & 0 \\
\hline FALF19 & V. ordalii & 0 & 0 & 0 \\
\hline FALF498 & V. ordalii & 0 & 0 & 0 \\
\hline FALF166 & V. ordalii & 0 & 0 & 0 \\
\hline FALF134 & V. ordalii & 0 & 0 & 0 \\
\hline FALF317 & V. ordalii & 0 & 0 & 0 \\
\hline FALF343 & V. ordalii & 0 & 0 & 0 \\
\hline FALF344 & V. ordalii & 0 & 0 & 0 \\
\hline FALF93 & V. ordalii & 0 & 0 & 0 \\
\hline SPRF217 & V. ordalii & 0 & 0 & 0 \\
\hline SPRF129 & V. ordalii & 0 & 0 & 0 \\
\hline SPRF206 & V. ordalii & 0 & 0 & 0 \\
\hline FALF36 & V. tasmaniensis & 1 & 0 & 0 \\
\hline 12E04 & V. tasmaniensis & 0 & 4 & 4 \\
\hline 13E05 & V. tasmaniensis & 0 & 5 & 5 \\
\hline $12 \mathrm{~F} 06$ & V. tasmaniensis & 1 & 0 & 0 \\
\hline 14G11 & V. tasmaniensis & 0 & 5 & 5 \\
\hline 14B04 & V. tasmaniensis & 0 & 5 & 5 \\
\hline $13 \mathrm{~B} 12$ & V. tasmaniensis & 1 & 0 & 0 \\
\hline FALF386 & V. tasmaniensis & 0 & 8 & 8 \\
\hline $13 \mathrm{~B} 11$ & V. tasmaniensis & 8 & 3 & 3 \\
\hline $13 \mathrm{G} 10$ & V. tasmaniensis & 0 & 5 & 5 \\
\hline FAL1300 & V. tasmaniensis & 0 & 4 & 1 \\
\hline 13B07 & V. tasmaniensis & 0 & 1 & 0 \\
\hline FALZ76 & V. tasmaniensis & 0 & 3 & 3 \\
\hline $13 \mathrm{H} 11$ & V. tasmaniensis & 0 & 3 & 3 \\
\hline $14 \mathrm{~F} 05$ & V. tasmaniensis & 0 & 10 & 10 \\
\hline FALF481 & V. tasmaniensis & 0 & 5 & 5 \\
\hline 14B07 & V. tasmaniensis & 0 & 6 & 6 \\
\hline
\end{tabular}




\begin{tabular}{|l|l|r|r|r|}
\hline \multicolumn{1}{|c|}{ isolate name } & \multicolumn{1}{|c|}{ population } & out-degree & in-degree & $\begin{array}{c}\text { in-degree (from } \\
\text { ordalii) }\end{array}$ \\
\hline $14 \mathrm{~B} 02$ & V. tasmaniensis & 0 & 5 & 5 \\
\hline $14 \mathrm{G} 06$ & V. tasmaniensis & 0 & 5 & 4 \\
\hline FALF350 & V. tasmaniensis & 0 & 6 & 6 \\
\hline FAL1292 & V. tasmaniensis & 0 & 0 & 0 \\
\hline FAL1293 & V. tasmaniensis & 0 & 0 & 0 \\
\hline FALF233 & V. tasmaniensis & 0 & 0 & 0 \\
\hline FAL5261 & V. tasmaniensis & 0 & 0 & 0 \\
\hline $13 F 02$ & V. tasmaniensis & 0 & 0 & 0 \\
\hline $14 \mathrm{H} 03$ & V. tasmaniensis & 0 & 0 & 0 \\
\hline $14 \mathrm{H} 05$ & V. tasmaniensis & 0 & 0 & 0 \\
\hline $14 \mathrm{G} 12$ & V. tasmaniensis & 0 & 0 & 0 \\
\hline $12 \mathrm{H} 02$ & V. tasmaniensis & 0 & 0 & 0 \\
\hline $12 \mathrm{H} 09$ & V. tasmaniensis & 0 & 0 & 0 \\
\hline $12 \mathrm{E} 09$ & V. tasmaniensis & 0 & 0 & 0 \\
\hline
\end{tabular}


Table S4. Accession numbers of 41 genome sequences used in gene content analysis (Fig S2).

\begin{tabular}{|c|c|c|}
\hline Bioproject ID & Accession number & Strain name \\
\hline PRJNA164629 & AJWN00000000 & Enterovibrio norvegicus FF-454 \\
\hline PRJNA164633 & AJYD00000000 & Enterovibrio norvegicus FF-33 \\
\hline PRJNA164635 & AJYE00000000 & Enterovibrio norvegicus FF-162 \\
\hline PRJNA164637 & AJYF00000000 & Enterovibrio calviensis FF-85 \\
\hline PRJNA164639 & AJYG00000000 & Enterovibrio calviensis 1F-211 \\
\hline PRJNA164641 & AJYH00000000 & Enterovibrio calviensis 1F-230 \\
\hline PRJNA164727 & AJYI00000000 & Aliivibrio fischeri ZF-211 \\
\hline PRJNA164729 & AJYJ00000000 & Aliivibrio logei 5S-186 \\
\hline PRJNA164805 & AJYK00000000 & Vibrio rumoiensis $1 \mathrm{~S}-45$ \\
\hline PRJNA164807 & AJYL00000000 & Vibrio breoganii ZF-55 \\
\hline PRJNA164811 & AJYM00000000 & Vibrio breoganii ZF-29 \\
\hline PRJNA164821 & AJYN00000000 & Vibrio genomosp. F10 str. 9ZB36 \\
\hline PRJNA164823 & AJYO00000000 & Vibrio genomosp. F10 str. 9ZD137 \\
\hline PRJNA164825 & AJYP00000000 & Vibrio genomosp. F10 str. 9ZC157 \\
\hline PRJNA164829 & AJYQ00000000 & Vibrio genomosp. F10 str. ZF-129 \\
\hline PRJNA164835 & AJYR00000000 & Vibrio ordalii FF-167 \\
\hline PRJNA164837 & AJYS00000000 & Vibrio ordalii FS-238 \\
\hline PRJNA164841 & AJYT00000000 & Vibrio ordalii FF-93 \\
\hline PRJNA164843 & AJYU00000000 & Vibrio ordalii FS-144 \\
\hline PRJNA164847 & AJYV00000000 & Vibrio ordalii 12B09 \\
\hline PRJNA167003 & AJYW00000000 & Vibrio genomosp. F6 str. FF-238 \\
\hline PRJNA167004 & AJYX00000000 & Vibrio kanaloae 5S-149 \\
\hline PRJNA167005 & AJYY00000000 & Vibrio crassostreae 9CS106 \\
\hline PRJNA167006 & AJYZO00000000 & Vibrio crassostreae 9ZC13 \\
\hline PRJNA167007 & AJZA00000000 & Vibrio crassostreae $9 \mathrm{ZC} 77$ \\
\hline PRJNA167008 & AJZB00000000 & Vibrio crassostreae 9ZC88 \\
\hline PRJNA167009 & AJZC00000000 & Vibrio crassostreae ZF-91 \\
\hline PRJNA167010 & AJZD00000000 & Vibrio splendidus $12 \mathrm{E} 03$ \\
\hline PRJNA167011 & AJZE00000000 & Vibrio splendidus ZS-139 \\
\hline PRJNA167012 & AJZF00000000 & Vibrio splendidus ZF-90 \\
\hline PRJNA167013 & AJZG00000000 & Vibrio splendidus 5S-101 \\
\hline PRJNA167014 & AJZH00000000 & Vibrio splendidus FF-500 \\
\hline PRJNA167015 & AJZI00000000 & Vibrio splendidus FF-6 \\
\hline PRJNA167016 & AJZJ00000000 & Vibrio splendidus $1 \mathrm{~F}-157$ \\
\hline PRJNA167017 & AJZK00000000 & Vibrio splendidus $0407 Z C 148$ \\
\hline PRJNA167018 & AJZL00000000 & Vibrio splendidus 1S-124 \\
\hline PRJNA167019 & AJZM00000000 & Vibrio tasmaniensis 1F-187 \\
\hline PRJNA167047 & AJZN00000000 & Vibrio tasmaniensis 1F-155 \\
\hline PRJNA167048 & AJZOO0000000 & Vibrio tasmaniensis 1F-267 \\
\hline PRJNA167049 & AJZP00000000 & Vibrio tasmaniensis 5F-79 \\
\hline
\end{tabular}




\begin{tabular}{|c|l|c|}
\hline Bioproject ID & \multicolumn{1}{|c|}{ Accession number } & Strain name \\
\hline PRJNA167050 & AJZQ00000000 & Vibrio tasmaniensis ZS-17 \\
\hline
\end{tabular}

\section{References}

1. S. Guindon, F. Delsuc, J. F. Dufayard, O. Gascuel, Estimating maximum likelihood phylogenies with PhyML. Methods Mol Biol 537, 113 (2009).

2. J. Felsenstein, Phylogeny Inference Package (Version 3.2). Cladistics 5, 164 (1989).

3. F. Chen, A. J. Mackey, C. J. Stoeckert, Jr., D. S. Roos, OrthoMCL-DB: querying a comprehensive multi-species collection of ortholog groups. Nucleic acids research 34, D363 (Jan 1, 2006).

4. W. W. Metcalf et al., Conditionally replicative and conjugative plasmids carrying lacZ alpha for cloning, mutagenesis, and allele replacement in bacteria. Plasmid 35, 1 (Jan, 1996).

5. C. Matsumoto-Mashimo, A. M. Guerout, D. Mazel, A new family of conditional replicating plasmids and their cognate Escherichia coli host strains. Research in microbiology 155, 455 (Jul-Aug, 2004).

6. A. E. Darling, B. Mau, N. T. Perna, progressiveMauve: multiple genome alignment with gene gain, loss and rearrangement. PloS one 5, e11147 (2010). 